\title{
CIÊNCIA-TECNOLOGIA-SOCIEDADE-AMBIENTE: UM DEBATE NECESSÁRIO NO ENSINO MÉDIO INTEGRADO (INSTITUTOS FEDERAIS DO BRASIL)
}

\author{
SCIENCE-TECHNOLOGY-SOCIETY-ENVIRONMENT: A NECESSARY \\ DEBATE IN INTEGRATED HIGH SCHOOL (FEDERAL INSTITUTES OF \\ BRAZIL)
}

\section{CIENCIA-TECNOLOGÍA-SOCIEDAD-MEDIO AMBIENTE: UN DEBATE NECESARIO EN LA ESCUELA SECUNDARIA INTEGRADA (INSTITUTOS FEDERALES DE BRASIL)}

\author{
Elizandra Sirlei Del Zotto Ritter ${ }^{1}$; Patricia Thoma Eltz ${ }^{2}$ \\ ${ }^{1}$ Instituto Federal Sul-rio-grandense - zandra.ritter@hotmail.com \\ 2 Instituto Federal Sul-rio-grandense - patriciaeltz@sapucaia.ifsul.edu.br
}

\begin{abstract}
Resumo: Os problemas ambientais com o quais a humanidade está se deparando são consequência da desenfreada depredação da natureza na contemporaneidade. No entanto, no âmbito dos estudos CTSA (Ciência-Tecnologia-Sociedade-Ambiente), os debates sobre os processos tecnocientíficos e seu impacto social são emergentes e necessários. O objetivo deste texto versa no movimento de inserção dos debates CTSA na etapa do Ensino Médio Integrado, como uma perspectiva formativa dos Institutos Federais do Brasil. Se deve a uma concepção de educação baseada na ação crítico reflexiva do sujeito para com seu meio, na proposição de uma formação integral que o prepara para o mundo do trabalho. São utilizados referenciais teóricos que incluem Ciavatta (2005), Frigotto (2008), Pinheiro; Silveira; Bazzo (2009), Nascimento; Rodrigues; Nunes (2016). Os resultados obtidos versam sobre uma proposta de currículo formativo que assume os debates CTSA de forma interdisciplinar aos demais saberes.
\end{abstract}

Palavras-chave: Estudos CTSA. Ciência-Tecnologia-Sociedade-Ambiente. Institutos Federais do Brasil.

\begin{abstract}
The environmental problems humanity is facing are a consequence of the rampant depredation of nature in contemporary times. However, within the scope of the CTSA (Science-Technology-Society-Environment) studies, debates about technoscientific processes and their social impact are emerging and necessary. The aim of this text is the insertion movement of the CTSA debates in the Integrated High School stage, as a formative perspective of the Federal Institutes of Brazil. It is due to a conception of education based on the reflexive critical action of the subject towards his environment, in the proposition of an integral formation that prepares him for the world of work. Theoretical references are used that include Ciavatta (2005), Frigotto (2008), Pinheiro; Silveira; Bazzo (2009), Nascimento; Rodrigues; Nunes (2016). The obtained results are about a proposal of formative curriculum that assumes the CTSA debates in an interdisciplinary way to the other knowledges.
\end{abstract}

Key words: CTSA Studies. Science-Technology-Society-Environment. Federal Institutes of Brazil.

Resumen: Los problemas ambientales que enfrenta la humanidad son consecuencia de la depredación desenfrenada de la naturaleza en los tiempos contemporáneos. Sin embargo, dentro del alcance de los estudios CTSA (Ciencia-Tecnología-Sociedad-Medio Ambiente), los debates sobre procesos tecnocientíficos y su impacto social son emergentes y necesarios. El propósito de este texto es el movimiento de inserción de los debates de CTSA en la etapa de la escuela secundaria integrada, como una perspectiva 


\section{prociênci@s}

\section{v. 2, n. 2, dezembro, 2019}

formativa de los Institutos Federales de Brasil. Se debe a una concepción de la educación basada en la acción crítica reflexiva del sujeto hacia su entorno, en la proposición de una formación integral que lo prepare para el mundo del trabajo. Se utilizan referencias teóricas que incluyen Ciavatta (2005), Frigotto (2008), Pinheiro; Silveira; Bazzo (2009), Nascimento; Rodrigues Nunes (2016). Los resultados obtenidos son sobre una propuesta de currículum formativo que asume los debates de CTSA de manera interdisciplinaria al otro conocimiento.

Palabras Ilave: Estudios CTSA. Ciencia-Tecnología-Sociedad-Medio ambiente. Institutos Federales de Brasil. 


\section{prociênci@s}

\section{v. 2, n. 2, dezembro, 2019}

\section{INTRODUÇÃO}

A tríade ciência, tecnologia e sociedade tem emergido nas discussões curriculares que perfazem o entendimento da multidisciplinaridade como propulsora formativa para o sujeito apto ao exercício da cidadania. A interdependência dos termos da tríade provoca a compreensão de que avanço tecnológico e ciência são inerentes ao contexto no qual se instalam. Desta forma, a realidade social que se abastece dos produtos consequentes deste emaranhado também se torna codependente do ambiente que possibilita os processos de transformação da natureza pelo homem.

Este texto debate a relevância das discussões dentro dos Institutos Federais do Brasil no âmbito do Ensino Médio Integrado, considerando a emergência dos temas socioambientais na proporção de um processo formativo responsável em sua complexitude.

Em um primeiro momento discorre-se sobre a interrelação entre ciência, tecnologia, sociedade e ambiente (CTSA) na proposição formativa dos Institutos Federais e o modo como os currículos de educação

profissional e tecnológica acompanham esta proposição. Para tal, subsidiam o debate: Ciavatta (2005), Frigotto (2008), Pinheiro; Silveira; Bazzo (2009) e Nascimento; Rodrigues; Nunes (2016). Posteriormente, são discutidas as possibilidades e desafios dos professores do Ensino Médio Integrado mediante os enlaces acometidos a partir da relevância social do debate CTSA.

\section{OS INSTITUTOS FEDERAIS DO BRASIL: UMA PROPOSTA FORMATIVA QUE CONSIDERA A RELEVÂNCIA DO DEBATE CTSA}

Esta discussão trata do entendimento da humanidade como transformadora de seu ambiente no contingente científico-tecnológico que abrange as realidades sociais em um tempo histórico específico, a contemporaneidade. Frigotto (2008) menciona o sujeito como produto e 


\section{prociênci@s}

\section{v. 2, n. 2, dezembro, 2019}

produtor de conhecimento social. Neste invólucro que considera a relação interdisciplinar dos saberes e a formação humana integral, desenvolve a ideia da necessidade da socialização do conhecimento. Necessidade esta inerente à subsistência humana, já que, apesar de identificarem-se as diversas dimensões de um contexto (político, social, cultural) e de um sujeito (biológico, intelectual, estético), jamais teríamos uma compreensão completa se qualquer um fosse ignorado.

O movimento de pensamento, instigado através desta introdução sobre a humanidade e seu trato com o ambiente onde se constitui, incita responsabilidade mediante escolhas. Assim como Frigotto trata de uma produção de conhecimento inerente a uma materialidade social, enfatiza a impossibilidade de ser neutra. E partindo deste entendimento, os debates da interrelação ciência-tecnologia-sociedade-ambiente (CTSA) chegam ao espaço institucional de ensino caracterizado como centros de pesquisa e inovação.

Os Institutos Federais do Brasil, intrínseca aos currículos dos cursos ofertados, possuem uma concepção sobre uma educação humanizadora que parte da necessidade de uma alfabetização científica. Cada qual respeitando sua regionalização e necessidades de sua comunidade, se configuram como espaços de produção de conhecimento relevante no patamar da educação profissional e tecnológica.

A responsabilidade sobre o ensino destes alunos perpassa a preparação para o mundo do trabalho. Trata-se de um comprometimento com a vida em sociedade. Assim, reconhecendo a contemporaneidade como um tempo de grandes problemáticas que envolvem ética e política, os processos movimentados pelas ciências não são mais eximíveis de seu cunho social. O ato educativo, portanto, preocupa-se com a formação de um sujeito corresponsável em seu meio.

Tendo o trabalho como principio educativo na perspectiva ontológica de constituir a existência humana, através do ato de educar e trabalhar, a proposta dos Ifes recepciona os estudos CTS e sua relação mais aprimorada com o ambiente em um proporção interlocutiva. Esta 


\section{prociênci@s}

v. 2, n. 2, dezembro, 2019

percepção abarca a ideia de que não somente as disciplinas de ciência debatam impactos ambientais, mas que todos os saberes sejam incorporados à vida humana como dimensões da sociedade (sujeito e meio).

Frigotto (2008) debate a transcendência do plano fenomênico tanto nos processos de pesquisa quanto no ato pedagógico. Esta inferência se dá pela sua percepção sobre os processos de submissão expressos socialmente em diferentes planos. A concepção de ensino federal profissional e tecnológico, ofertado através do Ensino Médio Integrado, contrapõe justamente a alienação pelo trabalho. Através do alinhamento entre ensino técnico e ensino intelectual que promove a valorização da cultura geral inerente ao ser humano, já que cada sujeito é um complexo em suas dimensões. Como poderia então ser formado em apenas alguns aspectos? E é exatamente neste ponto que Frigotto menciona um projeto educativo produtor de conhecimento em contraponto a outro reprodutor que cede a uma ordem tecnicista e alienante ao mercado.

Ainda, tratando das inovações tecnológicas e dos processos produtivos, as estratégias para a aprendizagem significativa incluem o estímulo à pesquisa, no âmago da produção cultural da humanidade, assim como a preservação do meio ambiente.

Quando se alinham pensar e agir, os conflitos de interesse eclodem. E neste compasso o espaço institucional como o dos Ifes, na promoção da alfabetização científica, reconhece a necessidade do trabalho que debate e entrelaça os termos ciência, tecnologia, sociedade e ambiente. Alinhando a proposta formativa dos Institutos Federais do Brasil e a prospecção CTSA interlocutiva aos currículos formativos na educação profissional e tecnológica, a etapa seguinte trata do reconhecimento de perspectivas e desafios a serem enfrentados. 


\section{prociênci@s}

\section{v. 2, n. 2, dezembro, 2019}

\section{ENSINO MÉDIO INTEGRADO: POSSIBILIDADES E DESAFIOS EMERGENTES DO DEBATE CTSA}

Os processos tecnocientíficos, inerentes à realidade social na qual se constituem, podem trazer benefícios ao mesmo passo em que prejuízos para a sociedade e o ambiente. O controle social da ciência e da tecnologia por meio de uma educação científica e tecnológica tem na etapa do Ensino Médio o espaço de formação capaz de produzir um conhecimento engendrado em valores necessários à tomada de decisões pertinentes a partir da resolução de problemas. O professor seria o interlocutor de saberes na proposição de projetos que visam a busca de soluções para problemas que envolvam ciência e tecnologia. $\mathrm{Na}$ perspectiva CTSA, segundo Pinheiro, Silveira e Bazzo (2009), para além das disciplinas de ciências, as estratégias de ensino precisam incluir as discussões sobre ciência e tecnologia em todo o conteúdo científico.

A liberdade democrática capaz de promover diálogos sobre os processos tecnocientíficos e seus efeitos sociais pode ser efetivada a partir de estratégias pedagógicas. As metodologias ativas, segundo a teoria de Seymor Papert (2007), que elevam o aluno à condição de locutor de debates, podem ser potenciais nos movimentos discursivos CTSA. Como exemplo, no relato de uma pesquisa que considera as metodologias ativas como motivadores do sujeito juvenil e arte educação, a partir da abordagem triangular para o ensino das artes de Barbosa (2010), alunos participaram de uma proposta que envolve jogos e a elaboração de regras de ação. $O$ trajeto de pesquisa envolvia os alunos na pesquisa sobre obras de arte e sua historicidade, assim como seu alinhamento com contextos atuais. Na mesma proporção das regras conhecidas pelos alunos sobre o jogo "UNO", imagens e informações foram sendo organizadas de modo que, a partir da dinâmica coletiva, o aprendizado significativo pudesse ser constituído de forma lúdica. O jogo, através de sua trajetória de planejamento, construção e validação, estimulou os jovens a socializarem para além de um conteúdo tradicional padrão. A construção do próprio 


\section{prociênci@s}

\section{v. 2, n. 2, dezembro, 2019}

caminho para sua aprendizagem coloca o aluno na posição de crítico sobre seu meio e as formas através das quais age em sociedade. (cf. HILDEBRAND; GOMES, 2007).

Como forma de identificar os processos através dos quais a sociedade se constitui e subsiste em seu meio, o exemplo acima desencadeia a memória cultural eternizada pela arte. Os alunos protagonizaram o processo de planejamento do material que subsidiaria a assimilação do conhecimento padrão em arte (produção de obras e respectivos períodos históricos). Além disso, a dinâmica do jogo promoveu o debate. Debate este que incitava não somente o produto-arte desenvolvido em seu tempo histórico, mas também sua relação com a realidade na qual foi constituído, trazendo, intrinsecamente, os valores sociais considerados. Os enlaces que a interdisciplinaridade de saberes proporciona potencializa a produção científica de conhecimento significativo em qualquer área ou disciplina base. No emaranhado do conhecimento complexo, quanto maior forem as interlocuções, maior será a compreensão sobre as dinâmicas socioambientais que se apresentam. Também maior será a cadeia de proposições sobre a resolução de problemas emergentes e possíveis.

A provocação proposta neste momento vincula a transposição didática dos conteúdos padrões através de estratégias pedagógicas que motivem o jovem a reconhecer e opinar sobre os processos de sua realidade social. Assim como no exemplo considerado acima, o professor era mediador no cenário dinâmico que foi instaurado na construção do jogo. O objetivo, para além da assimilação de conteúdo, potencializou discussões interdisciplinares sobre o meio social e como trabalhamos para que a sociedade continue se mantendo. E como os sistemas de manutenção são capazes de nos segregar e nos limitar.

Como trata Ciavatta (2005), o espaço educativo é um espaço que comporta diferentes e diversas identidades, eloquente em seu potencial de memória. Neste pressuposto, tomar o Ensino Médio como etapa de formação à vida considera mais que a formação para o mercado de 


\section{prociênci@s}

\section{v. 2, n. 2, dezembro, 2019}

trabalho. O Ensino Médio Integrado pretende romper a dicotomia entre saber intelectual e técnico. E os debates CTSA capacitam a interlocução necessária entre os saberes, as grandes áreas do conhecimento, reconhecendo a inovação tecnológica e o efeito do conhecimento científico produzido pela humanidade aplicado a seu ambiente. Neste entendimento, o trabalho é ferramenta que alinha ciência e produção. $\mathrm{Na}$ sociedade, todo sujeito trabalha, e se não o faz para sua subsistência é porque se mantém da exploração do trabalho do outro.

Toda esta criticidade sobre as relações que condicionam as dinâmicas sociais é produto de uma educação humanizada que reconhece o outro como aliado na manutenção da vida humana em seu ambiente. E trazendo para o universo juvenil, a qualidade de seu processo formativo pode configurar melhores condições ao ingresso no mundo do trabalho, que proporcione mais do que a mera adaptabilidade padrão:

\footnotetext{
Durante todo o século $X X$ podemos perceber que devido à especificidade da formação técnica, dada pelo caráter hegemônico da presença das indústrias e pela ausência de um projeto educacional que articulasse a cultura da escola com a cultura do trabalho, prevaleceu, na educação profissional e tecnológica, os fundamentos básicos e operacionais de preparação para o mercado de trabalho. (NASCIMENTO; RODRIGUES; NUNES, 2016, p. 3).
}

Em contraponto a esta manutenção sistêmica acima, uma nova visão da educação profissional e tecnológica foi implementada no final do ano de 2008, valorizando as instituições públicas. Nasce o Ensino Médio Integrado (Educação Profissional e Tecnológica de forma integrada com o Ensino Médio), ofertado pelas escolas técnicas brasileiras.

$\mathrm{Na}$ proporção de uma formação integral que compreenda a relevância da interdisciplinaridade, os Institutos Federais brasileiros constituíram seus próprios Planos Pedagógicos Institucionais (PPI`s) que consideram o contexto específico no qual cada instituição existe. Assim, também, conforme necessidade da própria realidade social da localidade, os cursos e seus respectivos Planos Pedagógicos (PPC's) foram se delineando. 


\section{prociênci@s}

\section{v. 2, n. 2, dezembro, 2019}

A formação do professor que estará mediando esta nova concepção de educação para a vida e para o mundo do trabalho precisa ter em sua formação inicial e continuada os preceitos que banham esta proposição crítico reflexiva de sujeito. Os debates sobre os impactos sociais e as relações de trabalho, consequentes de processos tecnocientíficos, são aliados enquanto ferramentas interdisciplinares para os professores. São capazes de movimentar dinâmicas emergentes de problemas sociais reais. CTSA, como elementos que representam a realidade político-social na qual a humanidade está imersa, alinham educação e trabalho na perspectiva da responsabilidade do sujeito para com seu meio. Logo, efetivam-se debates necessários dos problemas da sociedade contemporânea.

Os desafios que se apresentam estão relacionados com o sistema do capital que rege as relações de exploração pelo trabalho. Logo, os jovens, mesmo formados em uma concepção que os instigue a buscar por melhores condições de trabalho e direitos sociais, estarão enfrentando um mercado competitivo e excludente com níveis alarmantes de desemprego, em plena era da terceirização. A base formativa que têm proposta a partir da oferta no Ensino Médio Integrado dos Ifes fornecerão subsídios que somente uma formação integral compreende: uma educação profissional e tecnológica constituída nas perspectivas da diminuição entre trabalho técnico e trabalho intelectual.

Analisa-se, neste ponto, que a proposta formativa dos Ifes, portanto, subsidia oportunidades melhores no mundo do trabalho e na vida do sujeito. O que é pautado é uma nova concepção de educação de qualidade e gratuita que pensa e constrói o coletivo, sem desconsiderar o sujeito individual em sua identidade e historicidade: o considerando como parte integrante de um projeto maior para com seus pares, para com seu meio.

Sobre a relevância da inserção CTSA no projeto formativo direcionado a nossos jovens, Reguillo (2003) corrobora a ideia de que os jovens têm se movimentado na defesa de muitas pautas, inclusive relacionadas às questões ambientais. Isto porque o próprio movimento juvenil está propondo uma nova relação entre Estado e sociedade. (GIL; 


\section{prociênci@s}

v. 2, n. 2, dezembro, 2019

SEFFNER, 2016). Nesta mesma corrente, CTSA propõem uma nova relação entre humanidade e natureza, em prol da coexistência de ambos.

\section{CONCLUSÕES}

A perspectiva de inclusão necessária dos debates sobre a interlocução dos termos Ciência-Tecnologia-Sociedade-Ambiente (CTSA) é emergente, principalmente quando se pauta uma concepção de educação que considera o sujeito como ator em sua realidade social. Em um movimento crítico-reflexivo, como o promovido através da oferta formativa dos Institutos Federais do Brasil, o trabalho como essência da existência humana considera a natureza aliada à subsistência da vida. Assim, precisa- se buscar soluções efetivas para barrar os graves impactos ambientais decorrentes dos excessos humanos.

As metodologias ativas, que motivam os jovens a constituírem novas e diversificadas formas de debaterem e compreenderem sua realidade social ao mesmo passo em que produzem conhecimento acadêmico, são ferramentas capazes de potencializar estratégias pedagógicas.

CTSA, como conteúdos interdisciplinares, precisam circular entre os diferentes saberes, indo além das áreas das ciências naturais. No Ensino Médio Integrado, na Educação Profissional e Tecnológica, precisam movimentar a preocupação dos enlaces entre inovação tecnológica e impacto social. Os Institutos Federais, como centros de pesquisa, têm em seus professores os mediadores de processos de quebra de paradigmas e padrões estatizados. Estes, por sua vez, também precisam de uma formação incial e continuada que acompanhe as discussões CTSA.

As propostas expressas na concepção formativa de um sujeito humanizado para as causas de seu ambiente como um todo, sem que sejam desconsideradas quaisquer dimensões, promovem o pensar na mesma proporção do fazer. No entanto, o esforço expresso através desta concepção ainda está longe de acabar com o desemprego, ou a exploração pelo trabalho alheio, ou com a força que o capital tem sobre a 


\section{prociênci@s}

v. 2, n. 2, dezembro, 2019

humanidade e suas dinâmicas que a segregam.

O que se espera tange a valorização dos profissionais da educação e seu compromisso com os valores coletivos na mesma proporção de uma consciência individual que evolua para o bem estar coletivo. Para tal, debates CTSA são cotidianamente primorosos, além de movimentar a alfabetizar científica tão necessária no Brasil e no mundo. 


\section{prociênci@s}

\section{v. 2, n. 2, dezembro, 2019}

\section{REFERÊNCIAS}

CIAVATTA, M. A formação integrada: a escola e o trabalho como lugares de memória e de identidade. Trabalho Necessário, v.3, n.3, 2005.

Disponível em:

< http://www.uff.br/trabalhonecessario/images/TN_03/TN3_CIAVATTA.pdf> . Acesso em: 15 mar. 2018.

FRIGOTTO, Gaudêncio. A interdisciplinaridade como necessidade e como problema nas ciências sociais. Rev. Centro Educação e letras da Unioeste, vol. 10, n. 1, 2008. Disponível em: < http://erevista.unioeste.br/index.php/ideacao/article/view/4143>. Acesso em 02 nov. 2019.

GIL, Carmem Z. V.; SEFFNER, Fernando. Dois monólogos não fazem um diálogo: Jovens e ensino médio. Educação \& Realidade, Porto Alegre, v. 41, n. 1, p. 175-192, jan./mar., 2016. Disponível em: <https://seer.ufrgs.br/ educacaoerealidade/article/view/55947/0>. Acesso em: 02 nov. 2019.

HILDEBRAND, Hermes R.; GOMES, Silvia T. A aprendizagem ativa e a leitura de imagens artísticas por meio de um jogo. 26 Encontro da Associação Nacional dos Pesquisadores em Artes Plásticas. Memórias e Invenções. Campinas, SP, 25 a 29 Set.,2007. Anais. Disponível em: $<$ http://anpap.org.br/anais/2017/PDF/EAV/26encontro GOMES Silvia Trentin HILDEBRAND Hermes Renato.pdf>. Acesso em: 18 Out. 2019.

NASCIMENTO, A.S.G.; RODRIGUES, M. F. ; NUNES, A. O. A pertinência do enfoque ciência, tecnologia e sociedade (CTS) na educação profissional e tecnológica. RBEPT, vol. 2, n. 11, 2016. Disponível em:

<http://www2.ifrn.edu.br/ojs/index.php/RBEPT/article/view/5457>. Acesso em: 02 nov. 2019.

PINHEIRO, N. A. M.; SILVEIRA, R. M. C. F.; BAZZO, W. A. O contexto científico-tecnológico e social acerca de uma abordagem crítico-reflexiva: perspectiva e enfoque. Rev. Iberoamericana de Educación. V. 49, n. 1, 2009. Disponível em: <https://rieoei.org/RIE/article/view/2116>. Acesso em: 03 nov. 2019. 